\title{
İşgücü Verimliliği ve Öğrenen Örgüt İlişkisi: Otomotiv Sektöründe Bir Araştırma
}

\author{
Seda KAYAPALI YILDIRIM*, Gürkan ÇALMAŞUR**
}

Öz

Klasik örgüt tasarımının ötesine geçerek verimliliği artırmaya çalışmak yıllardır araştırmacıların inceleme konuları arasındadır. Özellikle insan kaynaklarının daha verimli hale getirilebilmesi için bir takım yöntemler ortaya atılmıștır. $\mathrm{Bu}$ örgütsel yöntemlerin en önemlilerinden birisi ise örgütsel öğrenmedir. Verimli olan işgücünün daha fazla örgütsel öğrenmeye katkı sunacağı ve öğrendikçe de işgücü verimliliğinin arttığı faydalı bir döngünün oluşacağı düşünülmektedir. Bu noktadan hareketle Türkiye Otomotiv Sektöründe otomobil üreten dört işletmenin 1999-2018 yılı arasındaki öğrenme eğrilerini ortaya çıkararak işgücü verimliliğinden nasıl etkilendiğini ortaya koymak amaçlanmıştır. Araştırmanın bulgularına göre iki işletme genel olarak öğrenen örgüt iken diğer iki işletmeyi öğrenen örgüt olarak kabul etmek mümkün değildir. Ayrıca işgücü verimliliği arttıkça örgütsel öğrenme düzeyi de artmaktadır. Son olarak işletmelerde yıllar geçtikçe örgütsel öğrenmenin artmadığı elde edilen önemli bir diğer sonuçtur.

Anahtar Kelimeler: Öğrenme, Öğrenen organizasyonlar, Verimlilik, İșgücü verimliliği, Otomotiv sektörü, Türkiye

\section{The Relationship between Organization Learning and Labor Productivity: A Research in Automotive Sector}

\begin{abstract}
Improving productivity by moving beyond the classical organizational design is one of the research areas for years and several methods have been proposed to make particularly human resources more productive. One of the most important organizational methods is organizational learning. It is assumed that a productive workforce would contribute to organizational learning and this learning would increase the workforce productivity. Departing from this point, the purpose of this study is to examine how four organizations in the Turkish Automative Sector are impacted by workforce productivity through the learning curves of these organizations between the years of 1999 and 2018. The findings of the study showed that it is not possible to consier the two organizations as the learning organization while the other two organizations are learning organizations. Additionally, as the workforce productivity increases, the organizational learning level

\section{Özgün Araștırma Makalesi (Original Research Article) \\ Geliş/Received: 04.12.2019 \\ Kabul/Accepted: 10.02 .2021 \\ DOI: https://dx.doi.org/10.17336/igusbd.651984}

* Doç. Dr., Atatürk Üniversitesi, İktisadi ve İdari Bilimler Fakültesi, Erzurum, Türkiye, E-posta: seda.yildirim@atauni.edu.tr ORCID https://orcid.org/0000-0003-4438-2445

${ }^{* *}$ Doç. Dr., Erzurum Teknik Üniversitesi, İktisadi ve İdari Bilimler Fakültesi, İktisat Bölümü, Erzurum, Türkiye, E-posta: gurkan.calmasur@erzurum.edu.tr ORCID https://orcid.org/0000-00028515-5719
\end{abstract}


increases. Another important finding from this study is that the organizational learning in organizations does not increase by time.

Keywords: Learning, Learning organizations, Productivity, Labor productivity, Automotive Sector, Turkey

\section{Giriş}

Örgütleri başarıya taşıyan en önemli faktörlerden birisi insan kaynağıdır. Taylor'dan bu yana araştırmacılar işgücü verimliliğini artırmak için birçok model öne sürmüş ve verimlilik örgütler için ana hedeflerin odak noktasını oluşturmuştur (Bingöl, 2010). Şiddetli rekabetin olduğu dinamik çevrelerde faaliyet gösteren örgütler, kıt kaynakları en iyi şekilde kullanabilmenin anahtarını ve buna bağlı olarak maliyetleri en aza indirmenin çeşitli yollarını aramaktadır. Bununla beraber maliyetler azaltılırken örgütlerin faaliyetlerinde aksamalar yaşanmamalı ve mal veya hizmet üretiminde inovasyon devam etmelidir. Bunu sağlayacak olan ise nitelikli insan kaynağıdır ve bu niteliğin yanında insan kaynağının desteklenmesidir. Bu bağlamda örgütler açısından insan kaynağına sağlanabilecek en önemli desteklerden birisi ise bilginin çevreden doğru bir şekilde elde edilebilmesi, depolanması ve gerekli kişilerle paylaşılmasıdır. Bu durum ile bağlantılı olarak birçok araştırmacının ilgisini çeken örgütsel öğrenme olgusu ortaya çıkmıştır. Birçok araştırmacı örgütsel olarak nasıl öğrenilebileceği ile alakalı modeller kurmuş ve öneriler sunmuştur. Ulusal ve uluslararası literatür bu kavramla ilgili oldukça zengindir. Bunun yanı sıra örgütsel öğrenmenin insan kaynağını nasıl etkilediği ile ilgili çeşitli araştırmalara rastlamak mümkündür (Solomon, 1994; Crossan, 1999; Naktiyok ve İşcan, 2014). Ancak bu araştırmalarda genel olarak anket yöntemiyle ölçme yapılmış ve örgüt üyelerinin algıları üzerine yoğunlaşılmıştır. Buna karşın örgütsel çıktılara odaklanarak öğrenme ve insan kaynakları verimliliği ilişkisini ortaya koymak oldukça önemlidir. Bu nedenle bu araştırmada örgütsel çıktılara dayanarak öğrenen örgütlerin ișgücü verimliliğiyle olan ilișkisinin incelenmesi amaçlanmaktadır.

\section{Kavramsal Çerçeve}

Bilgi ve deneyim kazanma süreci olarak ifade edilen öğrenme, bireyin çevresel koşullara göre öğrenerek davranışlarını buna göre değiștirmesidir (Knowles, 1998;124). Ayrıca bireyler elde ettiği bilgileri zihinsel süzgecinden geçirdikten sonrada öğrenebilmektedir (Schwartz, 1991). Bireysel öğrenme örgütler açısından oldukça önemlidir, çünkü bireyler, takım ve örgütlerin kilit taşını oluşturmaktadır. Senge' ye göre örgütler ancak öğrenen bireyler aracılığıyla öğrenebilir ve bununla birlikte bireysel öğrenme örgütsel öğrenmeyi garanti etmez; fakat bireysel öğrenme olmadan örgütsel öğrenme meydana gelemez. Bu nedenle bireysel öğrenebilen bilgi çalışanı olgusu örgütler için önemlidir.

Drucker 1959 yılında bilgi çalışanı kavramını eğitimsel, niteliksel ve de kuramsal açıdan analitik bilgi kazanabilme ve bunu pratiğe dönüştürebilme yeteneğine sahip insanları bulundurması gereken iş rollerini tanımlamak için kullanmıştır (Arthur vd., 2008). Buna ek olarak Drucker (2002) bilgi çalışanlarını sadece işgören olarak değil bir sermaye olarak görmüștür. Özellikle çevresel koşulların hızla değişmesi ve kaotik ortamda rekabetin şiddetlenmesi örgütlere yaratıcı olabilme zorunluğu getirmiștir. Bu çalkantılı çevresel şartlarda rekabet üstünlüğü sağlayabilmek ve belirsizliklerleler başa çıkabilmenin anahtarı bilgidir. Bu nedenle bilgi çalışanlarının koordineli bir şekilde bilgiyi elde etmeleri ve paylaşmaları ve bunun doğrultusunda karar almaları gerekmektedir. 
Örgütsel düzeyde öğrenme; örgütün çeșitli tecrübeler neticesinde bir bakış açısı ve anlayış elde etme kabiliyeti kazanması ayrıca gözlem, deney veya analizler sonucu çevreden edindiği verilere dayalı olarak yapmış olduğu hataları ve elde ettiği başarıları değerlendirme istekliliği olarak tanımlanmaktadır (McGill, Slocum ve Leı, 1992: 6). Örgütsel düzeyde öğrenme; sağlanan ortak anlayış ve değerlerin, örgütün bütünü için geçerli sistem, yöntem, prosedür, politika, beklenen davranış kalıpları ve her ihtiyacı olanın kolayca elde edebileceği ortak veri tabanlarına dönüștürülmesini ifade etmektedir. Organizasyonlarda öğrenme çeşitli düzeylerde öğrenme olayının gerçekleştiği bir süreç iken öğrenen organizasyon bu süreç sonucu ortaya çıkan yapıdır (Koçel, 2011;427). Öğrenen örgüt sürecin son aşaması olarak belirmektedir. Çevreden elde edilen bilgi ile ilişkilerini düzenleyen örgütler bilen örgütler olarak adlandırılırken, değișik iyilerin bulunabileceğini söyleyen organizasyon anlayan organizasyondur. Örgütlerin aksayan yönlerini yönetim teknikleri ile düzenleyen organizasyonlar ise düşünen örgüt ve nihayetinde öğrenmeyi teşvik eden, açık iletişimle bilgiyi paylaşan ve yapıcı bir ortam oluşturan örgütler, öğrenen örgüt olarak görülmektedir (McGill ve Slocum, 1993).

Senge (2000), öğrenen örgütlerin geleneksel örgütlerden farklılıklarını ortaya koymak için yaptığı araştırmalarda öğrenen örgütlerin belli temel disiplinlere hâkim olması gerektiğini tespit etmiştir. Senge (2000)'e göre örgütlerde öğrenmenin oluşabilmesi için beş disiplin olmalıdır. Bunlar; sistem düşüncesi, bireysel ustalık, zihni modeller, paylaşılan vizyon ve takım halinde öğrenmedir (Crandall, 2010;180). Bu durum ise işgücü verimliliği ile beraber örgütlerde öğrenmenin olabileceğinin bir göstergesidir.

Zihni modeller, zihnimizde yer edinmiş varsayımlar, genellemeler, semboller ve imgeler vasıtasıyla dünyayı kavrayışımızı ve davranışlarımızı etkileyen durumdur. Kişinin dünyayı sadece nasıl anlamlandırdığıyla kalmaz, eyleme geçiş şeklini de belirler (Senge, 2006, s.47-48). Paylaşılan vizyon, insanları doğru yönde hareket etmeye motive eder ve işgörenler arasında hızlı ve etkili bir biçimde koordinasyon sağlanmasına yardımcı olur. Vizyon, bir örgütün geleceğinin şekillenmesi ve gideceği yönün bulunması açısından son derece önemlidir ve öğrenen örgütler için paylaşılan vizyon kendini gerçekleștirme şartlarından biridir (Aybar ve Saldaml, 2016). Organizasyon içerisinde oluşturulan takımlar üyeyle örgüt arasında önemli bir köprü görevi görmektedir (Marquardt, 1996: 35). Örgütlerin öğrenme birimi vasfını taşıyan bireysel öğrenme artık takımlara doğru yönelmiştir. Bunun nedeni ise var olan sorunların bireysel çözümlemelerin ötesinde bir karmaşıklığa sahip olmasıdır. Bu denli kompleks bir sistem içerisinde ortaya çıkan problemlerin çözülebilmesi, yeteneğe sahip insanlardan oluşmuş takımların ortak zekâsı ve paylaşılan bilgi ile mümkün kılınabilir (Yazıcı, 2001: 163). Dolayısıyla insanlar ortak bir amaca yönelecek, karmaşık problemler çözülecek ve verimlilik artacaktır.

Birbirinde bağımsız gibi görünen durumları ve bu durumlar arasındaki ilişkileri sebep-sonuç ilişkisine dayandırarak farklılı̆̆ı bir bütün olarak ele alabilme becerisi sistem düşüncesini ifade eder (Senge, 2000: 15). Sistem düşüncesinin örgütü değerlendirme yaklaşımı, örgütü farklı bölümlerinin kendi aralarında ve çevreleri ile sürekli etkileşim içinde olduğu ve bu parçaların toplamından daha fazlasını içeren bir bütün olarak görmesine dayanır. Bu da bütünün parçalardan daha fazla olduğunu, diğer bölümlerin sinerjik etkisi ile gösterir (Naktiyok ve İşcan, 2014). Bununla beraber işletmede içinde bulunduğu endüstrinin bir alt parçasıdır ve bu alt parçalar endüstri içerisinde birbirinden etkileşim ile öğrenmektedir. Bu nedenle araştırmamızda otomotiv endüstrisinde faaliyet gösteren işletmeleri beraber incelemek amaçlanmaktadır.

Garvin'e (1993) göre bir örgüt bir malı veya hizmeti ürettikçe üretime ilişkin bilgilerinin artması ve bunun doğal bir sonucu olarak maliyetlerin düşmesi gerekmektedir. Bu noktadan hareketle işletme üretimi iki misline çıkardığında birim maliyetlerde \% 20 ila \% 30 arasında bir düşme gerçekleşmektedir. Bu ilişki ise tecrübe ve 
öğrenme ilişkisidir (Koçel, 2013; 433). Dolayısıyla bu araştırmada işgücü verimliliği arttıkça öğrenme düzeyinin de artacağını ortaya koymak amaçlanmaktadır.

Diğer yandan Schuman'ın yaklaşımına göre yüksek seviyede bireysel ustalığa sahip olan bilgi çalışanları, kendileri için önemli olan neticeleri tutarlı olarak yerine getirme yeteneğine sahiptir (Schuman, 2005). Yukarıda bilgi çalışanı olarak ifade edilirken açıklandığı gibi Senge (2000) tarafından da bireysel ustalık öğrenen örgütün temel taşı ve manevi temeli olarak ifade edilmektedir. Bir örgütün öğrenme isteği ve kapasitesi doğal olarak onu oluşturan insan kaynaklarında daha fazla olamaz. Bu nedenle gerçek bir öğrenen örgüt, üyelerinin bireysel ustalık düzeyini geliştirmeye çalışır (McCall, 1994). Sürekli olarak geleceğini nasıl şekillendireceğini öğrenen bir örgütün, yaşamlarında kendileri için önemli olan konularda nasıl gelişeceklerini öğrenen bireylerden oluşması beklenir (Timuroğlu vd., 2016). Bu beklentinin sonucu olarak öğrenen organizasyonlarda maliyetler düșecek ustalık becerileri yükselecek ve neticede işgücü verimliliği artacaktır.

\section{Yöntem}

Araştırmanın literatür kısmında bahsedildiği gibi öğrenmenin insan kaynağını nasıl etkilediği ile ilgili çeşitli araștırmalara rastlamak mümkündür (Solomon, 1994; Crossan, 1999; Naktiyok ve İșcan, 2014). Ancak bu araștırmalarda genel olarak anket yöntemiyle ölçme yapılmış ve örgüt üyelerinin algıları üzerine yoğunlașılmıștır. Buna karşın örgütsel çıktılara odaklanarak öğrenme ve insan kaynakları verimliliği ilişkisini ortaya koymak oldukça önemlidir. Bu nedenle bu araştırmada örgütsel çıktılara ele alınarak, öğrenen örgütlerin işgücü verimliliğiyle olan ilişkisinin incelenmesi amaçlanmaktadır. $\mathrm{Bu}$ araştırma, Atatürk Üniversitesi BAP birimi tarafından desteklenmiştir.

Türkiye otomotiv endüstrisinde faaliyet gösteren dört üretim tesisi için veriler, Otomotiv Sanayicileri Derneği'nden elde edilmiștir ve veri seti yıllık olarak 1999-2018 dönemini kapsamaktadır.

Türk otomotiv endüstrisinde 2018 yılında toplam 14 otomotiv üretim tesisi faaliyet göstermektedir (Otomotiv Sanayii Derneği, 2019). Bu üretim tesisleri otomobil, kamyon, kamyonet, otobüs, minibüs, midibüs ve traktör olmak üzere yedi farklı ürün üretmektedir. Bazıları bu ürünleri birlikte bazıları ise ayrı olarak üretmektedirler. Üreticilerin doğru olarak karşılaştırılabilmesi için analizler ilgili sektörde sadece otomobil üreten işletmeler dikkate alınarak yapılmıştır.

Wright'ın uçak endüstrisinde üretim maliyetlerini incelediği ve öğrenme eğrisi modelini analiz eden ilk yayın 1936'da yayınlanmıştır. Tek değişkenli ve çok değişkenli olmak üzere farklı öğrenme eğrisi modeli vardır. Geleneksel tek değişkenli öğrenme eğrisi, bağımsız değişken (kümülatif çıktı, vb.) açısından üretim maliyeti gibi bağımlı bir değişkeni sembolize eder. En ünlü tek değişkenli modeller log-lineer model, S-eğrisi, Stanford-B model, DeJong'un öğrenme formülü, Levy'nin adaptasyon işlevi, Glover'ın öğrenme formülü, Pegel'in üstel işlevi, Knecht'in düzelme modeli, Yelle'nin ürün modeli ve çarpma gücüdür (Yelle, 1979; Badiru, 1992; Asgari ve Gonzalez-Cortez, 2012).

Wright'ın (1936) çalışmasından günümüze, öğrenme eğrisi modelleri farklı endüstrilerde yaygın olarak kullanılmaktadır. Uçak endüstrisinde Hartley (1965), Argote \& Epple (1990); Yarı iletken endüstrisinde Boston Consulting Group (1973), Dick (1991) ve Chung (2001); gemi endüstrisinde Argote ve diğ. (1990); kimya endüstrisinde Lieberman (1984), Sinclair (2000); inşaat sektöründe Tan ve Elias (2000); imalat endüstrisinde Pramongkit ve diğ. (2002), Franceschini ve Galetto (2003), Karaöz ve Albeni (2005), Asgari ve Yen (2009), Asgari ve Gonzalez-Cortez (2012), Aduba ve Izawa (2018) öğrenme eğrisini analiz etmiştir. 
Öğrenme veya deneyim eğrisi, işletmenin kümülatif toplam çlktısı arttıkça ortalama maliyetteki düşüşü gösterir (Church ve Ware, 2000; Salvatore, 2003). Wright'ın modeli, doğrusal öğrenme eğrisini tahmin etmek için yaygın olarak kullanılan logdoğrusal model olarak adlandırılır. Model şu şekilde ifade edilebilir (Pramaongkit ve diğerleri, 2000; Pramaongkit ve diğerleri, 2002; Karaöz ve Albeni, 2005):

veya logaritmik formda eşdeğeri:

$$
C_{t}=C_{1} X_{t}^{-a}
$$

$$
\ln C_{t}=\ln C_{1}+a \ln X_{t}
$$

$\mathrm{C}_{\mathrm{t}}$ : $\mathrm{t}$ zamanındaki üretim düzeyi başına işgücü girdisini, $\mathrm{C}_{1}$ : ilk üretim düzeyini elde etmek için gereli olan işgücü girdisini, $X_{t}$ : $t$ zamanına kadar olan kümülatif üretim miktarını ve $-\alpha$ ise öğrenme esnekliğini temsil eder. Denklem 2'de yer alan $C_{t}$ yani t zamanındaki birim üretim maliyeti, kümülatif üretim seviyesini temsil eden $X_{t}$ ve üretim sürecinde ilk birimin üretim maliyetini gösteren $C_{1}$ 'in bir fonksiyonudur. Ayrıca, öğrenme etkisi ise $a$ 'nın değeri ile ölçülmektedir. $a$ 'nın değeri ne kadar büyük olursa, öğrenme etkileri de o kadar önemlidir. İlerleme oranı $(d)$ ise öğrenme esnekliğini temsil eden $a$ ile türetilmektedir. İlerleme oranı, kümülatif üretim seviyesi veya deneyim ikiye katlandığında birim başına maliyetin hangi oranda azaldığını göstermektedir. İlerleme oranı, $d=2^{-a}$ formülü ile hesaplanmaktadır (Pramongkit ve diğerleri, 2000; Pramongkit ve diğerleri, 2002; Karaöz ve Albeni, 2005; Aduba ve İzawa, 2018).

Herhangi bir işletme veya endüstride öğrenme söz konusu ise, ilerleme oranı değerlerinin sıfır ile bir arasında olması beklenir. İlerleme oranı değeri sıfıra yaklaştıkça daha iyi öğrenme olmaktadır. Bununla birlikte, bire yakın ilerleme oranı değeri düşük öğrenme oranını göstermektedir. Birden büyük bir ilerleme oranı ise öğrenme yerine unutma yaşandığını ifade eder. Yani, toplam üretim miktarı arttıkça birim üretim maliyetlerinde bir artış veya verimlilikte bir azalma gerçekleşmektedir. Ayrıca, ilerleme oranının değeri 1'e eşit olduğunda ne öğrenme ne de unutma söz konusudur (Argote \& Epple, 1990; Karaöz ve Albeni, 2005).

Öğrenme eğrisi etkisini ölçmek için yaygın olarak kullanılan geleneksel CobbDouglas üretim fonksiyonu işlevi şu şekilde ifade edilir:

veya logaritmik formda eşdeğeri:

$$
Q_{t}=A_{t} L_{t}^{\alpha} K_{t}^{\beta}
$$

$$
\ln Q_{t}=\ln A_{t}+\alpha \ln L_{t}+\beta \ln K_{t}
$$

$\mathrm{Q}_{\mathrm{t}}$; t yılındaki üretim düzeyini, $\mathrm{L}_{\mathrm{t}} ; \mathrm{t}$ yılındaki işgücü seviyesini, $\mathrm{K}_{\mathrm{t}} ; \mathrm{t}$ yılındaki sermaye düzeyini ve $A_{t}$, t yılındaki teknoloji seviyesini göstermektedir. $\alpha$ ve $\beta$ sirasıyla üretimin işgücü ve sermaye esnekliğidir. $\alpha$ ve $\beta$ parametrelerinin toplamı, ölçeğe göre getiriyi ifade etmektedir. $\alpha+\beta>1$ ise ölçeğe göre artan ve $\alpha+\beta<1$ ise ölçeğe göre azalan getiri vardır. $\alpha+\beta=1$ olduğu durumda ölçeğe göre sabit getiri söz konusudur (Pramaongkit ve diğerleri, 2002; Salvatore, 2003; Karaoz ve Albeni, 2005).

Denklem 3, $A_{t}$ ile $X_{t}$ arasında işlevsel bir ilişki olduğunu varsayar. Denklem 5 şöyle ifade edilir:

$$
A_{t}=H X_{t}^{a}
$$

veya logaritmik formda eşdeğeri:

$$
\ln A_{t}=\ln H+a \ln X_{t}
$$


Burada $H$ bir sabittir ve $X_{t}^{a}$, daha önce Denklem $1^{\prime}$ de $\left(X_{t}^{a}={ }^{C_{1}} / C_{t}\right)$ ile ifade edilen $X_{t}^{-a}$ 'nın tersidir. Dolayısıyla, $X_{t}^{a}={ }^{C_{1}} / C_{t}$ ilişkisini kullanarak, denklem 5'i şu şekilde yeniden yazabiliriz:

$$
A_{t}=H \frac{C_{1}}{C_{t}}
$$

doğal logaritma kullanarak doğrusal bir biçimde şöyle yazılabilir:

$$
\ln A_{t}=\ln H+\ln \left(\frac{C_{1}}{C_{t}}\right)
$$

Eğer denklem 4 ile denklem 6 birleștirilip $A_{t}$, yerine konulursa,

$$
\ln Q_{t}=\ln H+a \ln X_{t}+\beta \ln L_{t}+\gamma \ln K_{t}
$$

9 no.lu denkleminin her iki tarafından $\ln L_{t}$ ekleyerek ve sonuçları -1 ile çarparak,

$$
\ln (L / Q)_{t}=-\ln H-\alpha \ln X_{t}+(1-\beta) \ln L_{t}-\gamma \ln K_{t}
$$

Ek olarak, Denklem 10'da, sermaye ve emek arasındaki ilişkinin şöyle olduğu varsayılmaktadır:

$$
K_{t}=\mu L_{t}^{\lambda}
$$

veya doğal logaritmayı kullanarak, denklem aşağıdaki gibi yazılabilir:

$$
\ln K_{t}=\ln \mu+\lambda \ln L_{t}
$$

$\mu$ and $\lambda$ sabittir. $\lambda$ değeri, üretim artışına bağlı teknik önyargıları gösterir. . $\lambda=1$, teknolojik ilerlemede tarafsızlığı ifade ederken, $\lambda>1$, üretim seviyesi genişlemelerinin görüldügü üzere sermaye-emek oranının orantılı olarak arttığını öne sürmektedir (Pramongkit ve diğerleri, 2000; Pramongkit ve diğerleri, 2002; Karaoz ve Albeni, 2005). 13 eşitliği:

Denklem 10 ve denklem 12'yi birleștirme ve $\ln K_{t}$ yerine ikame edilerek denklem

$$
\ln (L / Q)_{t}=-\ln H-\gamma \ln \mu-\alpha \ln X_{t}+(1-\beta-\gamma \lambda) \ln L_{t}
$$

Denklem 13 doğrusal öğrenme modelidir. Öğrenme eğrisinin ampirik tahmini kullanılır. Daha kısa ifade etmek için $\sigma_{0}=-\ln H-\gamma \ln \mu, \sigma_{1}=-\alpha, \sigma_{2}=1-\beta-\gamma \lambda$, ve $\ln C_{t}=\ln (L / Q)_{t}$ olduğunu varsayarak,

$$
\ln C_{t}=\sigma_{0}+\sigma_{1} \ln X_{t}+\sigma_{2} \ln L_{t}+\varepsilon_{t}
$$

Kübik öğrenme modeli, öğrenme seviyesinin zaman içinde değiştiğini varsaymaktadır. Carlson (1973), K-öğrenme oranlarını tahmin etmek için S-eğrisi işlevinin kullanılmasını doğru gösterir. S-eğrisi işlevi, t sırasındaki üretim düzeyinin birim maliyetine göre, üçüncü dereceden polinomlu kümülatif üretimin bir işlevi olduğunu gösterir. Bu araştırmada, küp öğrenme modeli kullanıldı. Kübik öğrenme modeli şu şekilde ifade edilebilir (Badiru, 1992; Carlson, 1973; Karaoz ve Albeni, 2005, Asgari ve Yen, 2011):

$$
\ln C_{t}=\ln C_{1}+B \ln X_{t}+C\left(\ln X_{t}\right)^{2}+D\left(\ln X_{t}\right)^{3}
$$

15 no.lu eşitlik, t zamanındaki birim çıktı maliyeti başına kümülatif üretim seviyesinin bir fonksiyonudur. Öğrenme endeksi, Denklem 15'in ilk türevi ile belirlenir. 


$$
-a=\frac{d \ln C_{t}}{d \ln X_{t}}=B+2 C \ln X_{t}+3 D\left(\ln X_{t}\right)^{2}
$$

Ayrıca, Denklem 17, Denklem 15 'ten aşağıdaki gibi elde edilir:

$$
\ln \left(\frac{C_{1}}{C_{t}}\right)=-\left[B \ln X_{t}+C\left(\ln X_{t}\right)^{2}+D\left(\ln X_{t}\right)^{3}\right]
$$

$\ln \left(\frac{C_{1}}{C_{t}}\right)$ 8'deki Denklem 17 ile değiștirildiğinde. Yeni bir ilișki oluşur:

$$
\ln A_{t}=\ln H-B \ln X_{t}-C\left(\ln X_{t}\right)^{2}-D\left(\ln X_{t}\right)^{3}
$$

Denklem 18, Denklem 4'e eklenir ve așağıdaki form elde edilir:

$\ln Q_{t}=\ln H-B \ln X_{t}-C\left(\ln X_{t}\right)^{2}-D\left(\ln X_{t}\right)^{3}+\alpha \ln L_{t}+\beta \ln K_{t}$

Ek olarak, Denklem 19'da sermaye ile emek arasındaki ilişkinin şöyle olduğu varsayılmaktadır:

$$
K_{t}=\mu L_{t}^{\lambda}
$$

$\mu$ ve $\lambda$ sabittir. Bu denklemin logaritmik formu Denklem 19'a eklenebilir:

$$
\ln Q_{t}=\ln H-B \ln X_{t}-C\left(\ln X_{t}\right)^{2}-D\left(\ln X_{t}\right)^{3}+\alpha \ln L_{t}+\beta\left(\ln \mu+\lambda \ln L_{t}\right)
$$

denklemin her iki tarafına da $\ln L_{t}$ eklendikten sonra, aşağıdaki son denklem elde edilir:

$$
\ln \left(\frac{L}{Q}\right)_{t}=-\ln H-\beta \ln \mu+B \ln X_{t}+C\left(\ln X_{t}\right)^{2}+D\left(\ln X_{t}\right)^{3}+(1-\beta \lambda-\alpha) \ln L_{t}
$$

Daha kısa ifade etmek için, $\theta_{1}=-(\ln H+\beta \ln \mu), \theta_{2}=(1-\beta \lambda-\alpha) \ln L_{t}$ ve $\ln C_{t}=$ $\ln (L / Q)_{t}$ olduğunu varsayalım.

$$
\ln C_{t}=\theta_{1}+B \ln X_{t}+C\left(\ln X_{t}\right)^{2}+D\left(\ln X_{t}\right)^{3}+\theta_{2} \ln L_{t}
$$

Denklem 17'nin türevi bize aşağıda belirtilen öğrenme esnekliğini verir:

$$
-a=\frac{\partial C_{t}}{\partial X_{t}} \frac{X_{t}}{C_{t}}=B+2 C \ln X_{t}+3 D\left(\ln X_{t}\right)^{2}
$$

Regresyon analizi ile 23 no.lu denklemde yer alan B, C ve D parametreleri tahmin edilerek $\alpha$ 'nın değeri hesaplanmaktadır. $\alpha$ değerinin tespit edildikten sonra ise ilerleme oranını belirlemek için $d=2^{-a}$ formülünden faydalanılmaktadır.

Ayrıca, öğrenme düzeyi ile işgücü verimliliği ve işletme yaşı arasındaki ilișkiyi tahmin etmek için 25 no.lu denklemde yer alan model kullanılmıștır.

\section{Bulgular}

$$
d=\sigma_{1} \text { productivity }+\sigma_{2} \text { age }
$$

Türkiye'de otomobil üreticileri için 1999-2018 dönemi için öğrenme seviyesini belirlemek amaciyla Denklem 24 hesaplanmıștır. Tablo 1, kübik öğrenme modeli kullanılarak tahmin edilen katsayıları göstermektedir. Tablo 1'de tahmin edilen tüm modeller, \%1 önem düzeyinde (F değerleri) bir bütün olarak istatistiksel olarak anlamlıdır. Modellerin R ${ }^{2}$ değerleri \%49,2 ile \%95 arasında değișmektedir. Parametreler için hesaplanan t değerleri otomobil üreticilerinin çoğu için tahminlerin anlamlı olduğunu göstermektedir. 
Tablo 1. Kübik Öğrenme Modeli Kullanılarak Elde Edilen Tahmin Sonuçları

\begin{tabular}{|c|c|c|c|c|c|c|c|}
\hline \multirow{6}{*}{ 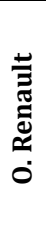 } & Değişken & Parametre & Katsayı & $\begin{array}{c}\text { Standart } \\
\text { Hata }\end{array}$ & $\begin{array}{c}t \\
\text { Değerleri }\end{array}$ & $\begin{array}{c}F \\
\text { Değerleri }\end{array}$ & $R^{2}$ \\
\hline & $\mathrm{C}$ & $\theta_{1}$ & $-212,08^{*}$ & 64,636 & $-3,28$ & \multirow{5}{*}{$\begin{array}{c}21,73^{*} \\
(0,000)\end{array}$} & \multirow{5}{*}{0,853} \\
\hline & $\ln X$ & $B$ & $45,779^{*}$ & 13,984 & 3,27 & & \\
\hline & $\ln X^{2}$ & $C$ & $-3,365^{*}$ & 1,025 & $-3,28$ & & \\
\hline & $\ln \mathrm{X}^{3}$ & $D$ & $0,082^{*}$ & 0,025 & 3,28 & & \\
\hline & $\operatorname{lnL}$ & $\theta_{2}$ & 0,344 & 0,312 & 1,10 & & \\
\hline \multirow{5}{*}{ 胥 } & $\mathrm{C}$ & $\theta_{1}$ & $-179,039^{* *}$ & 74,929 & $-2,39$ & \multirow{5}{*}{$\begin{array}{c}22,35^{*} \\
(0,000)\end{array}$} & \multirow{5}{*}{0,856} \\
\hline & $\ln X$ & $B$ & $41,721^{* *}$ & 18,091 & 2,31 & & \\
\hline & $\ln \mathrm{X}^{2}$ & $C$ & $-3,165^{* *}$ & 1,449 & $-2,18$ & & \\
\hline & $\ln X^{3}$ & $D$ & $0,079^{* * *}$ & 0,039 & 2,05 & & \\
\hline & $\ln L$ & $\theta_{2}$ & $-0,783^{*}$ & 0,237 & $-3,30$ & & \\
\hline \multirow{5}{*}{ 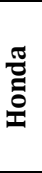 } & $\mathrm{C}$ & $\theta_{1}$ & $-183,894^{* *}$ & 79,933 & $-2,30$ & \multirow{5}{*}{$\begin{array}{c}3,63^{* *} \\
(0,029)\end{array}$} & \multirow{5}{*}{0,492} \\
\hline & $\ln X$ & $B$ & $53,939^{* *}$ & 22,281 & 2,42 & & \\
\hline & $\ln X^{2}$ & $C$ & $-5,149^{* *}$ & 2,053 & $-2,51$ & & \\
\hline & $\ln X^{3}$ & $D$ & $0,163^{* *}$ & 0,063 & 2,59 & & \\
\hline & $\ln L$ & $\theta_{2}$ & $-1,011^{* *}$ & 0,464 & $-2,18$ & & \\
\hline \multirow{5}{*}{$\begin{array}{l}\stackrel{\pi}{0} \\
\stackrel{0}{0} \\
\stackrel{0}{\circ}\end{array}$} & $\mathrm{C}$ & $\theta_{1}$ & $-43,111^{* * *}$ & 22,727 & $-1,90$ & \multirow{5}{*}{$\begin{array}{l}71,48^{*} \\
(0,000)\end{array}$} & \multirow{5}{*}{0,950} \\
\hline & $\ln X$ & $B$ & $13,279^{* *}$ & 5,274 & 2,52 & & \\
\hline & $\ln X^{2}$ & $C$ & $-1,052^{* *}$ & 0,413 & $-2,55$ & & \\
\hline & $\ln X^{3}$ & $D$ & $0,0278^{* *}$ & 0,011 & 2,60 & & \\
\hline & $\ln L$ & $\theta_{2}$ & $-1,799^{*}$ & 0,347 & $-5,19$ & & \\
\hline
\end{tabular}

Daha sonra, otomobil üreticileri için öğrenme seviyesi (ilerleme oranı), Tablo 2'de hesaplanmıș ve sunulmuştur. Yıllık öğrenme esneklikleri, Denklem 17'deki tahminler kullanılarak hesaplanmıştır. Sonra, bu esneklikler, $d=2^{-a}$ aracılığıyla yıllık öğrenme seviyesine (ilerleme oranı) dönüștürülmüștür.

1'in altındaki bir öğrenme seviyesi, öğrenmenin hala devam ettiğini gösterir; bu nedenle birim üretim maliyeti azalır ve toplam üretim arttıkça verimlilik artar. 1'in üzerindeki öğrenme seviyesi unutmayı gösterir; bu nedenle birim üretim maliyeti artar ve toplam üretim arttıkça verimlilik düşer. 1'e eşit bir öğrenme seviyesi, verimliliğin değişmediğini ve zaman içinde sabit kaldığını ima edilen bir gelişme veya kötüleșme olmadığını gösterir (Karaoz ve Albeni, 2005).

Tablo 2'deki yıllık öğrenme seviyesi, yıllar içinde ilgili tesis için iki katına çıkacak üretim karşısında birim üretim maliyetlerindeki düşüş veya artışı göstermektedir. Yıllık öğrenme seviyelerinin bir yıldan diğerine değişmesi, teknolojik öğrenme seviyesinin her yıl için farklı olduğunu göstermektedir. Örneğin, 1999, 2000 ve 2001' de O. Renault'un yıllık öğrenme seviyeleri sırasıyla 1.444, 0.954 ve 0.849 'dur. Bu sayılar, belirli bir yıl için elde edilen veya kaçırılan birim başına maliyet verimliliğini gösterir. Örneğin, 1999 yılında, 0. Renault'un üretim düzeyi iki katına çıkarken birim üretim maliyetleri $\% 44,4$ oranında artmış, ancak 2000 ve 2001 'de ise birim üretim maliyetleri sırasıyla $\% 4,6$ ve $\% 15,1$ oranında azalmıștır. Yani, 0 . Renault 2001'de daha iyi öğrenme düzeyine sahiptir. 
Tablo 2. Otomobil Üreticileri İçin Yıllık Öğrenme Seviyeleri

\begin{tabular}{|c|c|c|c|c|}
\hline $\begin{array}{c}\text { Firma } \\
\text { Yll }\end{array}$ & 0. Renault & Hyundai Assan & Honda & Toyota \\
\hline 1999 & 1,444 & 2,962 & 1,730 & 1,389 \\
\hline 2000 & 0,954 & 1,655 & 0,989 & 1,137 \\
\hline 2001 & 0,849 & 1,586 & 0,873 & 1,093 \\
\hline 2002 & 0,794 & 1,424 & 0,817 & 1,039 \\
\hline 2003 & 0,756 & 1,133 & 0,787 & 1,004 \\
\hline 2004 & 0,734 & 0,930 & 0,820 & 1,013 \\
\hline 2005 & 0,732 & 0,833 & 0,868 & 1,044 \\
\hline 2006 & 0,740 & 0,780 & 0,971 & 1,083 \\
\hline 2007 & 0,758 & 0,739 & 1,132 & 1,126 \\
\hline 2008 & 0,783 & 0,721 & 1,559 & 1,165 \\
\hline 2009 & 0,812 & 0,715 & 1,740 & 1,189 \\
\hline 2010 & 0,846 & 0,712 & 1,957 & 1,223 \\
\hline 2011 & 0,884 & 0,712 & 2,097 & 1,262 \\
\hline 2012 & 0,922 & 0,717 & 2,361 & 1,297 \\
\hline 2013 & 0,963 & 0,725 & 2,551 & 1,332 \\
\hline 2014 & 1,003 & 0,748 & 2,707 & 1,362 \\
\hline 2015 & 1,047 & 0,779 & 2,883 & 1,402 \\
\hline 2016 & 1,092 & 0,814 & 3,104 & 1,440 \\
\hline 2017 & 1,141 & 0,851 & 3,551 & 1,481 \\
\hline 2018 & 1,186 & 0,885 & 4,207 & 1,521 \\
\hline 0rt. & 0,922 & 1,021 & 1,885 & 1,230 \\
\hline
\end{tabular}

Tablo 3'te, öğrenme düzeyi ile işgücü verimliliği ve firma yaşı arasındaki ilişkiyi temsil eden 25 no.lu denklemden elde edilen tahmin sonuçları görülmektedir. İșletmeler için tahmin edilen modeller, \%1 önem düzeyinde (F değerleri) bir bütün olarak istatistiksel açıdan anlamlıdır. Modellerin $\mathrm{R}^{2}$ değerleri \%89,6 ile \%96,1 arasında değișmektedir.

Tablo 3. 25 no.lu Denklemin Tahmin Sonuçları

\begin{tabular}{|c|c|c|c|c|c|c|c|}
\hline \multirow{3}{*}{ 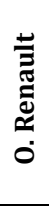 } & Değişken & Parametre & Katsayı & $\begin{array}{c}\text { Standart } \\
\text { Hata }\end{array}$ & $\begin{array}{c}t \\
\text { Değerleri }\end{array}$ & $\begin{array}{c}F \\
\text { Değerleri }\end{array}$ & $R^{2}$ \\
\hline & Verimlilik & $\sigma_{1}$ & $-0,011$ & 0,008 & $-1,37$ & \multirow[b]{2}{*}{$\begin{array}{l}222,21^{*} \\
(0,000)\end{array}$} & \multirow[b]{2}{*}{0,961} \\
\hline & $\begin{array}{c}\text { Firma } \\
\text { yașı }\end{array}$ & $\sigma_{2}$ & $0,037^{*}$ & 0,009 & 3,89 & & \\
\hline \multirow{2}{*}{ 宽 } & Verimlilik & $\sigma_{1}$ & $-0,071^{*}$ & 0,016 & $-4,44$ & \multirow{2}{*}{$\begin{array}{c}77,85^{*} \\
(0,000)\end{array}$} & \multirow[b]{2}{*}{0,896} \\
\hline & $\begin{array}{c}\text { Firma } \\
\text { yaşı }\end{array}$ & $\sigma_{2}$ & $1,228^{*}$ & 0,137 & 8,98 & & \\
\hline \multirow{2}{*}{ 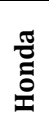 } & Verimlilik & $\sigma_{1}$ & $-0,003$ & 0,007 & $-0,44$ & \multirow{2}{*}{$\begin{array}{c}199,51^{* *} \\
(0,000)\end{array}$} & \multirow[b]{2}{*}{0,957} \\
\hline & $\begin{array}{c}\text { Firma } \\
\text { yașı }\end{array}$ & $\sigma_{2}$ & $0,167^{*}$ & 0,014 & 11,56 & & \\
\hline \multirow{2}{*}{$\begin{array}{l}\frac{\pi}{0} \\
0 \\
0 \\
0\end{array}$} & Verimlilik & $\sigma_{1}$ & 0,016 & 0,013 & 1,26 & \multirow{2}{*}{$\begin{array}{l}109,26^{*} \\
(0,000)\end{array}$} & \multirow[b]{2}{*}{0,924} \\
\hline & $\begin{array}{c}\text { Firma } \\
\text { yaşı }\end{array}$ & $\sigma_{2}$ & $0,049^{* *}$ & 0,022 & 2,26 & & \\
\hline
\end{tabular}

*ve ** sırasıyla \% 1 ve \% 5 önem düzeylerinde istatistiksel anlamlılı̆̆ı göstermektedir. 
Tablo 3'te görüldügü gibi, Toyota firması haricinde diğer tüm firmalar için öğrenme düzeyi ile verimlilik arasında negatif bir ilişki bulunmaktadır. Bu durum beklentileri karşılamaktadır. Yani, ilgili işletmelerin işgücü verimliliklerinin artması daha iyi bir öğrenme düzeyini ifade etmektedir. Ayrıca, tüm işletmeler için firma yaşı ile öğrenme düzeyi arasında pozitif bir iliş̧i tespit edilmiştir. Bu durum, firma yaşının artması ile öğrenme düzeyinin azaldığı anlamına gelmektedir.

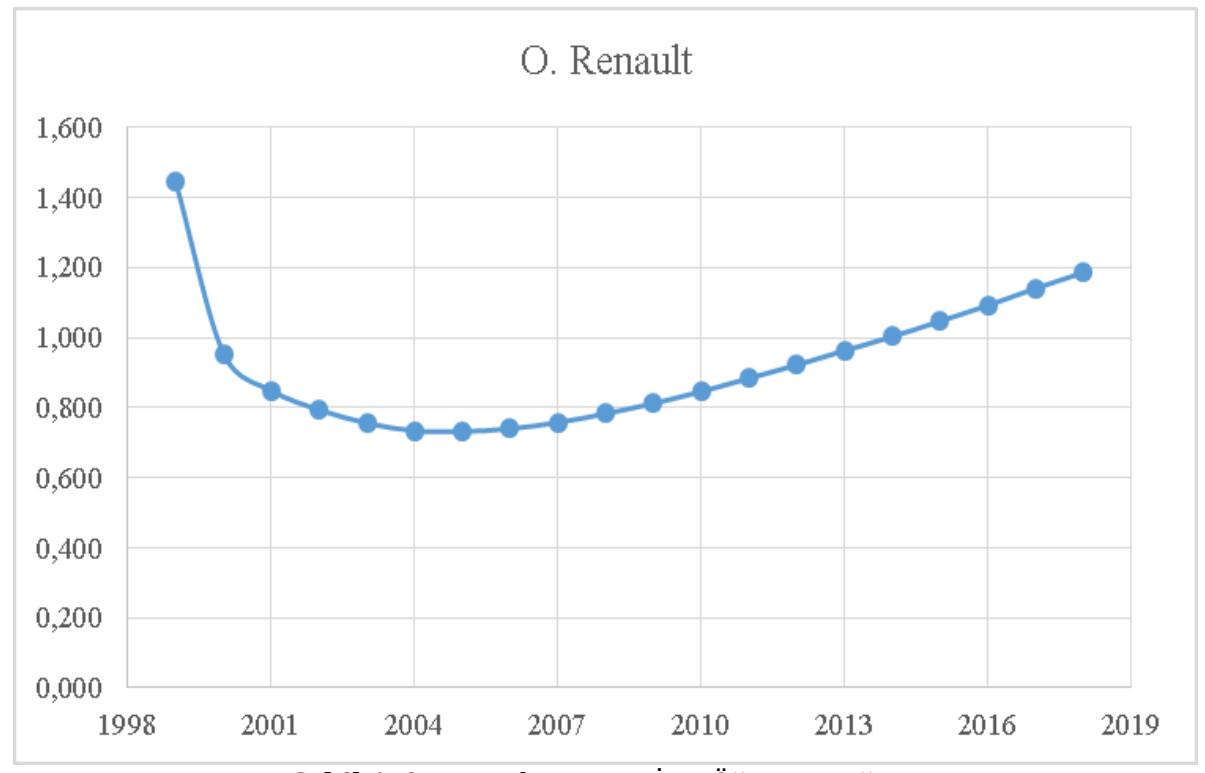

Şekil 1. O. Renault Firması İçin Öğrenme Eğrisi

Şekil 1, Tablo 2'de yer alan öğrenme seviyelerinden hareketle türetilen 0. Renault firmasının 1999-2018 dönemine ait öğrenme eğrisi görülmektedir. Şekil 1'de de görüldüğü gibi 0 . Renault firmasının öğrenme eğrisi U biçimindedir. Öğrenme düzeyi, 2005 yılına kadar sürekli azalan bir seyir izleyerek 2005 yılında minimum değerine ulaşmış ve söz konusu yıldan sonra ise giderek artan bir seyir izlemiştir. Daha önce de ifade edildiği gibi 1 değerinin altındaki bir öğrenme seviyesi, öğrenmenin hala devam ettiğini ve 1 değerinin üzerindeki öğrenme seviyesi ise unutmayı göstermektedir. Dolayısıyla ilgili değerlerin 1'den büyük olması olumsuz bir durum ve 1'den küçük olması ise olumlu bir durumu yansitmaktadır (Argote \& Epple, 1990; Karaöz ve Albeni, 2005). Firma en iyi performansını öğrenme düzeyinin rakamsal olarak en düşük olduğu 2005 yılında gerçekleștirmiştir $(0,732)$. Bu durum 1'in altında en iyi öğrenme düzeyini göstermektedir.

Şekil 2, Tablo 2'de yer alan öğrenme seviyelerinden hareketle elde edilen Hyundai Assan firmasının 1999-2018 dönemine ilișkin öğrenme eğrisini temsil etmektedir. Şekil 2'ye göre Hyundai Assan firmasının öğrenme eğrisi de U şeklindedir. Öğrenme düzeyi, 2011 yılına kadar sürekli azalan bir seyir izleyerek 2011 yllında minimum değerine $(0,712)$ ulaşmış ve 2011 yılından sonra ise giderek artan bir seyir izlemiştir. 1999-2003 yılları arasında firma unutma yaşarken, 2004-2018 döneminde ise firmanın öğrenme düzeyleri 1'den küçük olduğu için öğrenme devam etmiştir. 


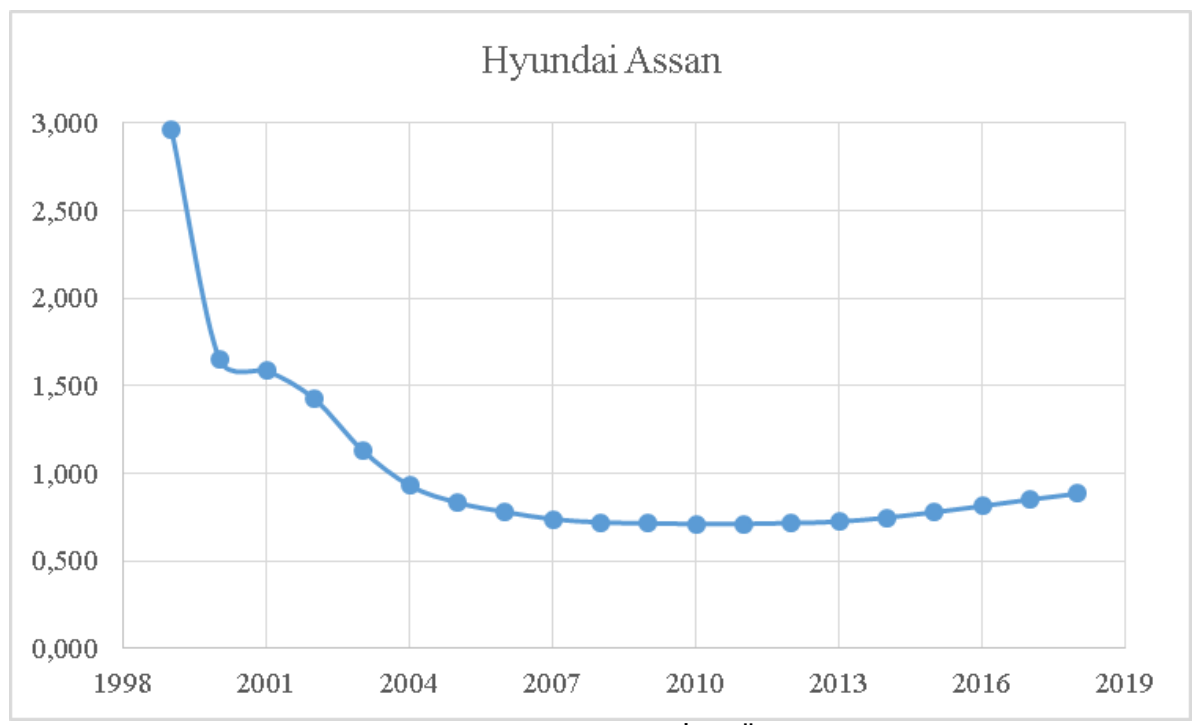

Şekil 2. Hyundai Assan Firması İçin Öğrenme Eğrisi

Şekil 3, Tablo 2'de yer alan öğrenme seviyelerinden hareketle elde edilen Honda firmasının 1999-2018 dönemine ilişkin öğrenme eğrisini temsil etmektedir. Şekil 3'de Honda firmasının öğrenme eğrisinin U biçimine sahip olduğu görülmektedir. Öğrenme düzeyi, 2003 yılına kadar sürekli azalan bir seyir izleyerek 2003 yılında minimum değerine ulaşmış ve bu yıldan sonra ise giderek artmaya başlamıştır. Firma en iyi performansını öğrenme düzeyinin en düşük olduğu 2003 yılında gerçekleștirmiștir $(0,787)$.

\section{Honda}

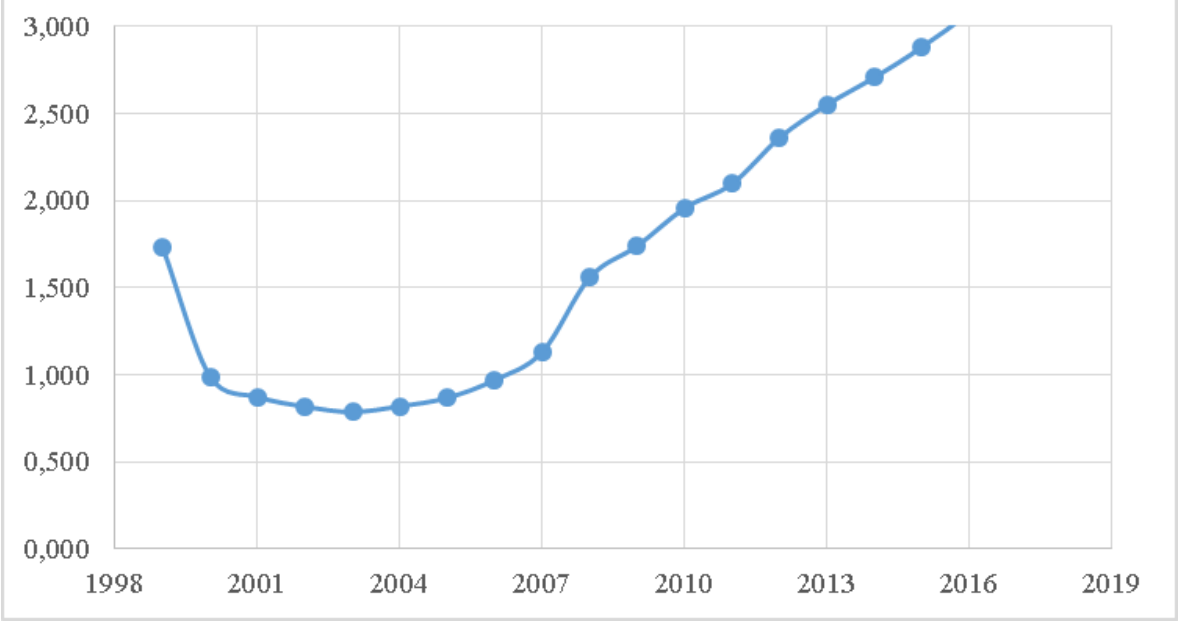

Şekil 3. Honda Firması İçin Öğrenme Eğrisi 
Şekil 4, Tablo 2'de yer alan öğrenme seviyelerinden hareketle elde edilen Toyota firmasının 1999-2018 yılları arasındaki öğrenme eğrisini temsil etmektedir. Şekil 4'e göre Toyota firmasının öğrenme eğrisi de diğer tüm firmalarda olduğu gibi $U$ biçimindedir. Öğrenme düzeyi, 2003 yılına kadar sürekli azalan bir seyir izlemiş ve 2003 yılında minimum değerine $(1,004)$ ulaşmış ve söz konusu yıldan sonra ise giderek artan bir seyir izlemiştir. Firmanın öğrenme düzeyleri 1'den büyük olduğu için tüm yllarda unutma yaşanmıştır.

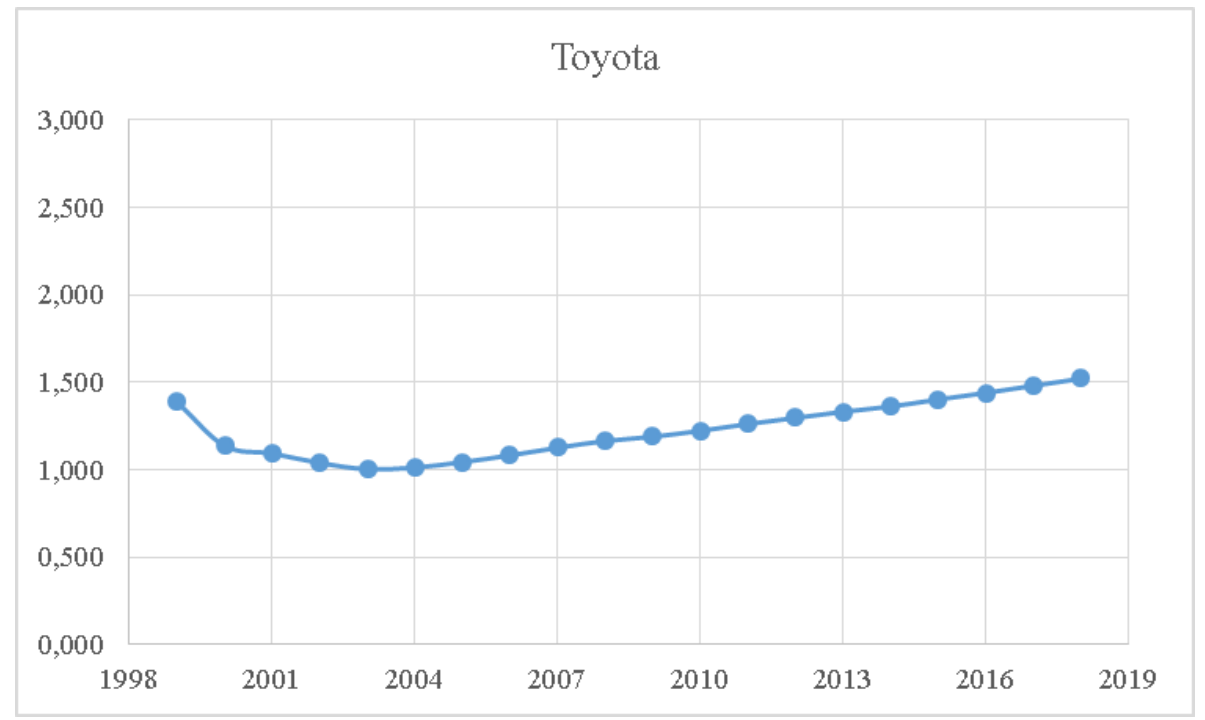

Şekil 4. Toyota Firması İçin Öğrenme Eğrisi

1999-2018 yılları arasında firmaların ortalama öğrenme seviyeleri dikkate alındığında O. Renault firması en iyi performansa sahip firmadır. İlgili dönemde firmada ortalama öğrenme seviyesi ortalama 0,922 olarak gerçekleșmiştir. Yani, firmanın üretim düzeyi iki katına çlkarken birim üretim maliyetleri 1999-2018 döneminde ortalama \%7,8 oranında azalmıştır.

\section{Tartışma ve Sonuç}

İşgücü verimliliğinin örgütsel öğrenmeyi nasıl etkilediğini ortaya koymak amaciyla Türkiye otomotiv sektöründe sadece otomobil üreten dört işletme üzerinde gerçekleștirilen araştırmanın sonuçlarına göre 0 Reanault ilk yıl ve son beş yıl unutmuşken diğer yıllarda öğrenmiștir. O Renault öğrenme ortalaması 0,922 ile genel olarak öğrenen bir örgüttür. Hyundai Assan 1999'dan bu yana ilk beş yıl unutan bir örgütken sonraki yılların hepsinde öğrenen bir örgüt haline gelmiștir. Hyundai Assan firması genel olarak 1,021 ile unutma eğilimi gösterirken bunun nedeni ilk beş yılın ilerleme oranlarının yüksek seyir izlemesidir. Fakat firma 2004'den bu yana hep öğrendiği için genel olarak öğrenen bir işletme olarak kabul edilebilir. Honda ilk başlarda öğrenen bir seyir izlerken 2007'den bu yana sürekli unutmuştur. 1,885 ortalama ile Honda'yı öğrenen bir örgüt olarak kabul etmek pek mümkün değildir. Toyota ise 1999 yılından bu yana unutan bir örgüt seyri izlemiştir ve genel ortalaması 1,230'dur. 
Araştırmanın esas amacını oluşturan işgücü verimliliği ve öğrenen örgüt ilişkisine bakıldığında İşletmelerin işgücü verimliliği arttıkça öğrenme düzeylerinin de arttığı tespit edilmiştir. İlgili denklem gereği öğrenme katsayısı 1'in üstüne çıktıkça unutan örgüt olarak değerlendirilmektedir. Dolayısıyla regresyon analizinde negatif ilişki çıkması sonucu işgücü verimliliği arttıkça öğrenen örgüt düzeyinin arttığını göstermiștir. Bu durum kavramsal çerçevede oluşturduğumuz beklentileri karşılamaktadır. Aybar ve Saldamlı (2016) otel işletmelerinde anket yöntemiyle elde ettikleri verilere yaptıkları analiz sonucu işgücü verimliliği ve örgütsel öğrenme arasında anlamlı ve olumlu ilişkiler tespit etmişlerdir. Bu noktada araştırmamızın örgütsel çıktılara dayalı olarak bunu ortaya koyması önemlidir. Yıldırım (2018) halı imalat sektöründe yaptığı araştırmada örgütsel öğrenme ve personel güçlendirme arasında anlamlı ve olumlu ilişkiler ortaya koymuştur. Bu nedenle işletmelere, işgücü verimliliğini yükseltmek ve dolayısıyla örgütsel öğrenme düzeyini artırabilmek için personel güçlendirme uygulamalarından faydalanmaları önerilir. Daha açık bir ifade ile işletmeler adem-i merkeziyetçi bir yapı, takım çalışması, kararlara katılım, eğitim, açık görüşlülük ve vizyonun paylaşımı gibi uygulamaları örgütsel yapılarına uzmanca entegre etmelidir.

Araştırmadan elde edilen bir diğer sonuca göre işletmenin yaşı ilerledikçe öğrenme düzeyinin azaldığı tespit edilmiştir. Bu işletmeler açısından istenen bir sonuç değildir ve Türkiye'deki otomotiv sektörüyle ilgili önemli bir durumu ortaya çıarmıştır. Bu durum öğrenmenin yaşa bağlı olarak kendiliğinden gerçekleşmediğinin buna karşın çabaya bağlı olarak gerçekleştiğinin göstergesidir. Etkili örgütsel davranışın, yalnızca deneysel öğrenme yoluyla elde edilen görev ustalığı ile değil, aynı zamanda uygun bir örgütsel ortam gerektirdiğini ortaya çıkaran teorileri kanıtlamaktadır (Edmondson, 2003; Edmondson, Bohmer ve Pisano, 2001; Pisano, Bohmer ve Edmondson, 2001). Bu nedenle Türkiye'deki otomotiv üreticileri öğrenmeye uygun örgütsel tasarımı oluşturmalıdır. TATA Motor ve bazı otomobil üreticileri özellikle çeşitli fonksiyonel departmanların bir otomobil modeline kolektif katkılarını koordine etmek için araç entegrasyon yöneticileri birimi olușturan mühendisler istihdam etmektedir (Shelton, 2003). Stan (2013) sağlık sektöründe yaptığı bir araștırmada benzer bir birimin örgütsel öğrenmeye önemli katkılar sunduğunu çalıșma takımlarını olumlu etkilediğini, bilgi paylaşımını organize ettiğini ve çapraz görevlerdeki birimleri aynı hedeflere yönelttiğini tespit etmiştir. Bu nedenle Türkiye'deki otomotiv üreticilerine örgütsel öğrenmeyi organize edecek koordinasyon birimlerinin oluşturulması önerilmektedir.

\section{Araştırmanın Sınırlılıkları ve Gelecek Araştırmalara Öneriler}

Bu araştırma Türkiye'de sadece otomobil üreten otomotiv işletmeleri üzerinde gerçekleștirilmiştir. Tüm otomotiv endüstrisinin ortalamaları değerlendirilip başka ülkelerdeki ortalamalarla karşılaștırılması önerilmektedir. Araştırmanın tartışma bölümünde başka endüstrilerdeki araștırmalarla değerlendirmeler yapılmıştır ancak gelecek araştırmalara nicel olarak başka endüstrilerinin verileriyle de karşılaştırma yapılması önerilmektedir. Örgütsel öğrenme düzeyinin yüksek olduğu tespit edilen organizasyonların vak'a olarak incelenmesi gibi yapılacak nitel çalışmalar da araştırmacılar için önerilmektedir.

Ayrıca örgütsel düzeyde öğrenme çıktıları ile bu tür bir öğrenmenin gerçekleşmesini artıran veya azaltan biçimsel yapı unsurları arasındaki ilişkiye dair sınırlı sayıda ampirik araştırma bulunmaktadır (Hyatt ve Ruddy, 1997; Pelled vd., 1999). Araştırmamızda olduğu gibi örgütsel öğrenme eğrilerine bakılmış olan çalışmalarla beraber takım kompozisyonu ve personel güçlendirme gibi diğer mikro bağlamdaki davranışsal faktörlere odaklanan araştırmalarında ortaya konulması önerilmektedir. 


\section{KAYNAKÇA}

ADUBA, J. J., IZAWA, H., (2018). “Industry (Economic)-Wide Learning: A Comparative Study of Manufacturing and Non-Manufacturing Sector in Japan." Asian Journal of Economics, Business and Accounting, vol. 9(4) pp. 1-14.

ARGOTE, L., EPPLE, D., (1990) "Learning Curves in Manufacturing." Science, vol. 247(4945), pp. 92-924.

ARGOTE, L., BECKMAN, S. L., EPPLE, D., (1990). “The Persistence and Transfer of Learning in Industrial Settings." Management Science, vol. 36(2) pp. 140-154.

ARTHUR MICHAEL, B., (2008). "On Being a Knowledge Worker", Organizational Dynamics, Vol. 37, No. 4, ss. 365-377.

ASGARI, B., GONZALEZ-CORTEZ, J. L., (2012). "Measurement of Technological Progress through Analysis of Learning Rates; the Case of the Manufacturing Industries in Mexico." Ritsumeikan Journal of Asian Pacific Studies, vol. 31, pp. 101-119.

ASGARI, B., YEN, L. W., (2009). “Accumulated Knowledge and Technical Progress in Terms of Learning Rate; A Comparative Analysis on the Manufacturing Industry and Service Industry in Malaysia." Asian Journal of Technological Innovation, vol. 17(2), pp. 71-99.

AYBAR, Sibel, SALDAMLI, Asım, (2016). "Otel İşletmelerinde Öğrenen Örgüt Yapısı ve Verimlilik İlișkisi”, İstanbul Ticaret Üniversitesi Sosyal Bilimleri Dergisi, Yıl:15 Sayı:29 Bahar s.371-390.

BADIRU, B. A., (1992). “Computational Survey Univariate and Multivariate Learning Curve Models." IEEE Transaction on Engineering Management, vol. 39, pp. 176188.

BİNGÖL, Dursun, (2010). Insan Kaynakları Yönetimi, İstanbul: Beta Yayın.

BOSTON CONSULTING GROUP, (1970). Perspectives on Experience. Boston,

Boston: Boston Consulting Group.

BOSTON CONSULTING GROUP, (1973). The Experience Curve-Reviewed II: History, Perspectives. Boston, Boston: Boston Consulting Group.

CARLSON, J. G., (1973). “Cubic Learning Curves: Precision Tool for Labor

Estimating." Manufacturing Engineering and Management, vol. 71(5), pp. 22-25.

CHUNG, S., (2001). "The Learning Curve and the Yield Factor: The Case of Korea's

Semiconductor Industry." Applied Economics, vol. 33(4) pp. 473-483.

CHURCH, J., WARE, R., (2000). Industrial Organization: A Strategic Approach.

Boston, Boston: McGraw Hill.

CROSSAN, Marry, (1999). An Organizational Learning Framework: From

Intiution to Institution, The Academy of Management Review, July, 522.

DICK, A. R., (1991). "Learning by Doing and Dumping in the Semiconductor

Industry." Journal of Law and Economics, vol. 34(1), pp. 133-159.

DRUCKER, Peter F., (2002). "They're not employees, They're People”, Harvard

Business Review, vol:80, no: 2, ss.70-77.

EDMONDSON, A. C., (2003). Speaking up in the operating room: how team

leaders promote learning in interdisciplinary action teams. Journal of Management Studies, 40(6): 1419-1452.

EDMONDSON, A. C., BOHMER, R. M. \& PISANO, G. P., (2001). Disrupted routines:

Team learning and new technology implementation in hospitals. Administrative Science Quarterly: 685-716.

FRANCESCHINI, F., GALETTO, M., (2002). "Asymptotic Defectiveness of Manufacturing Plants: An Estimate Based on Process Learning." International Journal of Production Research, vol. 40(3) pp. 537-545. 
GARVIN, David, (1993). "Building a Learning Organization”, Harvard Business Review, July-August, ss.80-89.

HARTLEY, K., (1965). "The Learning Curve and Its Application to the Aircraft Industry." The Journal of Industrial Economics, vol. 13(2), pp. 122-128.

HYATT, D. E. \& RUDDY, T. M., (1997). "An examination of the relationship between work group characteristics and performance: Once more into the breech”. Personnel Psychology, 50(3): 553-585.

KARAOZ, M., ALBENI, M., (2005). “Dynamic Technological Learning Trends in Turkish Manufacturing Industries.” Technological Forecasting and Social Change, vol. 72(7) pp. 866-885.

KNECHT, G. R., (1974). “Costing Technological Growth and Generalized Learning Curves." Operations Research Quarterly, vol. 25(3) pp. 487-491.

KNOWLES, Malcolm Shepherd (1998). The Adult Learner: The Definitive Classic in Adult Education and Human Resource Development, 5th Edition, Gulf Professional Publishing, Houston, USA.

KOÇEL, Tamer, (2011). İşletme Yöneticiliği, Beta Basım, 13. Baskı, İstanbul.

LEVY, F. K., (1965). "Adaptation in the Production Process." Management Science, vol.11 pp. 136-154.

LIEBERMAN, M. B., (1984). "The Learning Curve and Pricing in the Chemical Processing Industries." The RAND Journal of Economics, vol. 15(2), pp. 213-228.

MARQUARDT, J. M., (1996). Building the Learning Organization: A Systems Approach to Quantum Improvement and Global Success. Mcgaw Hill, New York. s.143

McCALL JOHN R., (1994). The principal's edge, Eye on Education, New York, USA,

McGILL, M. SLOCUM, J. LEI, D., (1992). "Management Practices in Learning Organizations". Organizational Dynamics, 21 (1).

McGILL, M. SLOCUM, J., (1993). “Unlearning the Organization”. Organizational Dynamics, Fall, 67-74.

NAKTIYOK, S., İSCAN, O.F., (2014). Çalışanların Örgüte Olan Bağlılıklarında Bir Öncül Olarak Örgütsel Öğrenmenin Rolü, Kafkas Üniversitesi İ̈BF Dergisi, 5,7.

PELLED, L. H., EISENHARDT, K. M. \& XIN, K. R., (1999). Exploring the black box: An analysis of work group diversity, conflict, and performance. Administrative Science Quarterly, 44(1): 1-3.

PISANO, G. P., BOHMER, R. M. J. \& EDMONDSON, A. C., (2001). Organizational Differences in Rates of Learning: Evidence from the Adoption of Minimally Invasive Cardiac Surgery. Management Science, 47(6): 752-768.

PRAMONGKIT, P., SHAWYUN, T., SIRINAOVAKUL, B., (2002). "Productivity

Growth and Learning Potentials of Thai Industry." Technological Forecasting and Social Change, vol. 69(1), pp. 89-101.

SALVATORE, D., (2003). Microeconomics: Theory and Applications. New York, New York: Oxford University Press.

SCHUMAN, Sandy, (2005). The IAF handbook of group facilitation: best practices from the leading organization in facilitation, John Wiley and Sons, San Francisco, USA, s.70.

SCHWARTZ, Barry ve REISBERG, Daniel (1991). Learning and Memory, W. W.

Norton \& Company, Scranton, Pennsylvania, U.S.A, ss.2-20.

SENGE, Peter M., (2006). Beşinci Disiplin: Öğrenen Organizasyon Düşünüşü ve Uygulaması, (Çev: Ayșegül İldeniz ve Ahmet Doğukan), 13. Baskı, Yapı Kredi Kültür Sanat Yayıncllık Ticaret ve Sanayi A.Ş., İstanbul, Ocak.

SENGE, P. M., (2000). Beşinci Disiplin: Öğrenen Organizasyon Düşünüşü ve Uygulaması. (Çev. Aysegül İldeniz-Ahmet Doğukan). İstanbul: Yapı Kredi Yayınları. 
SHELTON, M., (2003). Managing your integration manager. McKinsey Quarterly.

SINCLAIR, G., KLEPPER, S., COHEN, W., (2000). "What's Experience Got to Do with it? Sources of Cost Reduction in a Large Specialty Chemicals Producer."

Management Science, vol. 46(1), pp. 28-45.

SOLOMON, Charlene M., (1994). HR Facilitiates the Learning Organization Concept, Personel Journal, November, 59.

STAN, M., (2013) Aiding Organizational Learning: The Case of Integrators in Fertility Care. (GSTF Conference Proceedings on EMG \& Bizstrategy 2013 ). Global Science and Technology Forum (GSTF)

TAN, W., ELIAS, Y., (2000). "Learning by Doing in Singapore Construction." Journal of Construction Research, vol. 1(2), pp. 151-158.

TIMUUROĞLU M. K., NAKTIYOK A., KULA M.E., (2016). Strategic Thought and Learning Orientation, South Asian Journal of Management, 23-4, ss.7-30.

OTOMOTIV SANAYIII DERNEĞİ, OSD Üyeleri, Erişim tarihi: 21.11.2019, http://www.osd.org.tr/osd-uyeleri/

WILLIAM, Crandall, (2010). Crisis Management in the New Strategy Landscape, SAGE Publications, California, USA, , s.180.

WRIGHT, T. P., (1936). "Factors Affecting the Cost of Airplanes." Journal of the Aeronautical Sciences, vol. 3, pp. 122-128.

YAZICI, S., (2001). Öğrenen Organizasyonlar. İstanbul: Alfa Yayınları.

YELLE, L. E., (1979). "The Learning Curve: Historical Review and Comprehensive Survey." Decision Science, vol. 10(2), pp. 302-328.

YILDIRIM, F., (2018). "The Mediator Role of Employee Empowerment on the Effect of Organizational Learning on Innovation", Istanbul Gelisim University Journal of Social Sciences 5 (2), October pp. 18-38.

\section{Summary}

Learning, defined as the process of acquiring information and knowledge, is adaptation and change of one's behaviors through learning according to environmental factors. Additionally, individuals can also learn after zognitively filtering the information they obtain. Individual learning is important for organizations as individuals constitute the key stone of teams and organizations. According to Senge, organization can onlu learn through individuals that are learning; however, individual learning does not guarantee organizational learning but organizational learning can't occur without individual learning. Therefore, the concept of knowledge worker who can learn individually is important.

According to Garvin (1993), when an organization produces a product or service, information related to production should increase and as a natural result the costs should decrease. Departing from this point, when an organization increases production twice as much, a 20\% to 30\% decrease in unit costs occur. This relationship is the experience and learning relationship. Thus, the purpose of this study is to show that as workforce productivity increases, the level of learning would also increase.

On the other hand, according to Schuman's approach, knowledge workers that have high levels of personal mastery have the skills to reach outcomes accurately. As explained previously, Senge (2000) also describes personal mastery as the fundamental block and moral-foundation of a learning organization. The willingness and the capacity to learn of an organization can not be more than the human resources that constitutes the organization. That is why a real learning organization tries to improve its member's personal mastery levels. An organization that constantly learns how to shape its future is expected to consist 
of members that learn how to improve themselves in areas that are important in their lives. As a result of this expectation, costs will decrease, mastery skills will increase and as a result workforce productiviy will increase in learning organizations.

This study focusing on how workforce productivity influences organizational learning was conducted with four organizations that only manufactures cars in the automotive industry in Turkey. The results of the study showed that $O$ Renault has forgotten in the first and last five years while it learned in the recet years. $O$ Renault is a learning organization with a mean learning score of 0.922. Hyundai Assan was a forgetful organization in the first 5 years since 1999, it became a learning organization in the following years. Hyundai Assam organization shows tendency of forgetfulness with a score of 1.021 because the progression ratios in the first five years are high. However, as the organization has been learning since 2004, it can be cosnidered as a learning organization generally. Honda had a learning curve in the beginning but has been in the forgetting zone since 2007. It is not possible to consider Honda as a learning organization with a mean of 1.885. Toyota has been a forgetting organization since 1999 and its mean is 1.230.

The relationship between workforce productivity and learning organization showed that as the workforce productivity of organizations increase, their learning levels increase as well. Due to the related equation, as the learning coefficient goes above 1 , the organization is considered to be a forgetting organization. Therefore, negative results in regression analyses showed that as workforce productivity increases, the level of the learning organization increased. This finding supports our assumptions within the conceptual framework. Aybar and Saldamli (2016) idenfitied significant and positive relationships between workforce productivity and organizational learning. At this point, it is important that the current study identified this based on the organizational outcomes of our study.

Another finding of the study showed that as the age of the organization increases, the level of learning decreases. This is not a desired result by organizations and this finding revealed an important situation in relation to the automotive sector in Turkey. This indicates that learning does not occur by itself due to age but due to effort. It supports the theories that effective organizational behavior does not only occur due to personal mastery as a result of experiential learning, but also an organizational environment. Thus, automobile manufacturers in Turkey should create an organizational design that is compatible with learning. TATA Motors and certain automobile manufacturers employ engineers that constitute the vehicle integration managers unit in order to coordinate the collective contributions of various functional departments to an automobile model. Stan (2013) showed in their study in healthcare industry that a similar unit contributes to organizational learning, that it influences work teams positively, organizes information sharing and directs units in cross works to same goals. 